\title{
Bartolomé o de la dominación (fragmento) *
}

\author{
AUGUSTO SALAZAR BONDY
}

Estos diálogos indianos están escritos a mantera de ejercicios ideológicos de tema libre. Sin embargo, su argumento es imaginario sólo en un sentido figurado. Me extrañaria que toda semejanza con ideas, textos, situaciones o personas de la vida real fuese pura coincidencia.

A. S. B.

Don Diego.-Según me anuncian, has pedido ăudiencia para hablarme de cosas graves y que me conciernen.

Bartolomé-Así es, Diego; te conciernen a ti y a todos los cristianos que hemos llegado a estas tierras.

DON DiEgo._Veo que no vienes solo. ¿Quién te acompaña?

BARTOLOME.--Un buen amigo mío, del que seguramente has oído hablar: Hatuey, cacique de Guahabá. Cuando acepte el bautizo se llamará Ernesto, bello nombre que significa «combatiente decidido». Así lo llamo yo desde ahora.

Don Diego.—¿Hatuey? Sí que lo conozco. Su gente ha causado más daño a mis hombres que todas las tribus de la isla juntas...

* El presente diálogo de A. Salazar Bondy (Lima, 1926-1974) apareció póstumamente en el mismo año de la muerte de su autor y puede encontrarse -entre otros lugares - en el volumen Dominación y liberación (Estudios de A. S. B., 1966-1974), editado por Helen Orvig y David Sobrevilla, Fondo Editorial de la Universidad Nacional Mayor de San Marcos, Lima, 1995, pp. 191-264, el segundo de los cuales nos recuerda en su Introducción (pp. 15-64) que «Salazar había recibido una formación fenomenológica durante su estudio con José Gaos en México y luego en París y Munich, lo que se puede comprobar fácilmente de su tesis de 1953 Ensayo sobre la distinción entre el ser irreal y el ser ideal. Posteriormente profundizó su interés por el marxismo y lo estudió a fondo... como se advicrte de los artículos que publicó desde 1957 en el periódico Libertad y de otros trabajos. Por último, el filósofo peruano realizó a partir de los años sesenta una serie de lecturas de filosofía analítica, lo que se puede ver de sa artículo "Tendencias contemporáneas de la filosofía moral británica" de 1961 (luego en Para una filosofia del valor, 1971)... Examinando los planteamientos de Salazar se puede establecer claramente que su programa filosófico buscaba integrar en su obra y superar a través de ella las tres grandes tendencias filosóficas de nuestro tiempo en las que él.se había educado y que consideraba ligadas a los centros de poder existentes: la filosofia fenomenológica, el marxismo y la filosofia analítica. A la vez, quería que su filosofia no reprodujera la dominación existente en el Perú, sino que preparara su liberación» (pp. 16-7). 
BARTOLOME.-Viene pacíficamente y sin armas. Le he dado palabra de que no le harás daño alguno. Comprendo que hice mal en permitirme hablar en nombre de Don Diego, Gobernador y Repartidor Real de los Indios. Te ruego excuses esta libertad que me he tomado, pero el caso es que el cacique de Guahabá viene a comunicarte hechos que debes conocer, y también quiere hacerte una propuesta justa. A mi modo de ver, ella es capaz de asegurar que la ley de Dios impere en esta isla. Óyenos juntos, Diego, y júzganos de buena fe.

Don Diego.-iNo sé cómo te atreves tú a traerlo y él a presentarse ante mí! Sabes que anda haciéndonos resistencia; se niega a aceptar el dominio del Rey y la verdad de nuestra santa religión. Con su gente, en el bosque, solivianta a los indios, y cuando no lo escuchan o no lo siguen los castiga con el pillaje y la muerte. Es un enemigo mortal de la ley y la paz en esta isla. QQue se cuide mucho de intentar aquí alguna de sus bellaquerías! En esta breve tregua que concedo, te tomo como garante; tu cabeza será la prenda. iRecuérdalo bien!

BARTOLOMÉ.-De acuerdo. Nada arriesgo en este trato, pues Ernesto es hombre de palabra y su causa justa. Soy solidario con su pueblo en la lucha que ha emprendido y lo que voy a declararte no es, por cierto, extraño al ideal que persigue combatiendo. Por eso he pedido hablarte junto con él.

Don Diego.-Habla, pues.

Bartolomé.-Diego, amigo, en las Sagradas Escrituras está dicho «que es mancillada la ofrenda del que hace sacrificios de lo injusto; que el que ofrece sacrificios de la hacienda de los pobres es como el que degüella a un hijo; que quitar el pan del sudor es como el que mata a su prójimo». La palabra de Dios es inconfundible y me señala el único camino posible. Por eso vengo a hacer ante ti acto público de renuncia de la encomienda que me otorgaste y del privilegio, que de este modo me fue concedido por la Corona, de tener a mi cargo indios siervos. Los libero de todo servicio y dependencia respecto a mí a fin de que tú, como es tu obligación de cristiano, los pongas en libertad.

Don Diego.-Porque te he contado siempre entre mis amigos había rechazado ciertos rumores que me llegan sobre ti. Me han dicho que últimamente te las das de defensor de los indios y opositor de la encomienda. Con pena advierto que es verdad y que estás a punto de traicionar a tu Dios y a tu patria.

BarTolomé.-Ni a uno ni a otra. Por el contrario, quiero de todo corazón que mi Rey no se condene y que en sus dominios nadie incumpla los mandamientos del Dios verdadero. Así como mis hermanos de orden lo hicieron una vez conmigo, permitiéndome lavar mi alma del pecado de la encomienda, así desde hoy rehusaré la absolución a todo aquel que conserve un reparto de naturales y los haga trabajar como siervos suyos, o intervenga en cualquier expedición de conquista de territorios indios por la violencia. 
Don Diego.- ¿Qué pretendes con ello? Sería la alteración total del orden que con tantos afanes y con tanta sangre hemos establecido en estas tierras.

BARTOLOMÉ.-Tú lo has dicho, un orden establecido con sangre, sobre todo con sangre india. Hipócritamente, bajo la máscara de la encomienda, hemos esclavizado a los indios. Con el pretexto de hacerlos cristianos hemos impuesto por la fuerza de las armas un dominio que no sólo sujeta el territorio de este continente a nuestra ley, sino que aplasta las almas y apaga en ellas toda chispa de divinidad. Las almas humanas son brotes difíciles que languidecen en el cautiverio. Esta gente era antes bella, libre, dueña de sí. Su ser está ahora disminuido, su conciencia alienada; deambulan como extraños en un mundo que antes comprendían y que ahora está para ellos lleno de signos indescifrables.

Don Diego.-Bonita manera de no decir abiertamente que los naturales son tan bárbaros que no pueden siquiera hablar nuestra lengua. $Y$ eso no es nada. Tú no puedes ignorar su bestialismo: se matan entre ellos, son apocados, ociosos, incapaces de civilizarse por sí mismos, no tienen seso alguno y están corrompidos por los vicios más degradantes.

Bartolomé.-Pues ante ti hay alguien que puede convencerte de que el don del pensamiento no es privilegio de los blancos. Ernesto tiene argumentos que conviene atender para pacificar tu gobernación.

Don Diego.-Explícate, indio, si puedes, pero cuida bien de no decir ninguna insolencia y más aún de blasfemar.

Hatuey.-Hace algunos días tus soldados entraron en Caonao buscando hombres para hacer esclavos y oro. No encontraron eso; mataron a los niños, a las mujeres, a los viejos, todos sin armas; destruyeron las casas por odio.

Bartolomé.-Yo estuve allí; puedo dar fe de ello pues lo vi con mis propios ojos. Fue horrible.

Hatuey.-Lo mismo en Guernica, en Lídice, en Mi-Lay, en Wiriyamu. No puedo comprender a los cristianos. Dicen que su religión y su ley son de amor y de justicia, pero veo siempre crueldad y avaricia en sus hechos. ¿Esa es tu moral, Don Diego?

Don Diego.-ZQué quieres de mí? Habla.

HATUEY.--Hablo por el pueblo que sufre. Queremos que acabe ese maldito y viciado reparto de indios que con sus enormes excesos nos han puesto en estado tan deplorable, robándonos lo poco que teníamos, obligándonos casi a lamer la tierra. Queremos que cesen de explotarnos, y no lo que hacen ahora, cazándonos como a bestias del bosque y llevándonos ensartados a trabajar los cañaverales, a las minas, a los obrajes, desde las dos de la mañana hasta la hora en que aparecen las estrellas. Queremos que nos traten como a cristianos y no nos repriman a sangre y fuego, matándonos como a perros, echando nuestros cuerpos a los campos para que se los coman los buitres, y que no asesinen a nuestras mujeres y a nuestros hijos en los pechos de sus madres. Queremos la paz y la libertad de los hombres verdaderos, y lucharemos por ellas hasta la muerte. 
Bartolomé.-Creo, Diego, que deseas sinceramente aliviar el sufrimiento de los indios. Por eso he persuadido a Ernesto a hacerte una propuesta y sellar un trato en nombre de Cristo.

Don Diego.-iPero si es un pagano!, ¿́cómo va a prometer nada por Dios?

Bartolomé.-Óyelo, te lo ruego. Si aceptas la propuesta y se cumple la palabra empeñada, yo tendré franquía para penetrar en el bosque a predicarles la fe de Nuestro Señor y habrá paz.

HaTUEY.-Don Diego, si tú castigas a los criminales y no permites más expediciones de conquista, yo suspendo el combate y Bartolomé puede entrar donde mi gente. Eso propongo hacer en un año. Después puede haber nuevo trato.

Bartolomé-Recuerda, Gobernador, que la salvación de sus almas y las nuestras, la del Rey inclusive, está en juego. Acabemos con una guerra que nos degrada a todos y cumplamos nuestra verdadera misión: hacer que los indios alcancen la conciencia del Dios y eleven su ser hacia Él.

DON DieGo.- Yo cumplo el deber que me ha impuesto el Rey, y haciéndolo no me siento degradado en un ápice. Al contrario, mi conciencia me dice que estoy llamado por el destino a servir así a mi Dios y a mi patria.

HATUEY.-Los cristianos hablan mucho de conciencia y de ser, de salvación y de alma. Olvidan lo importante: muerte, dolor, hambre. Mi gente sufre eso día y noche; lo sentimos y odiamos sufrirlo; queremos libertad de no sentir hambre, de no oír llorar a los hijos, de no soportar el dolor de los huesos quebrados uno a uno, de no ser escupidos, pateados, asesinados.

BARTOLOME.-Te comprendo, hermano. No quiero para nadie la humillación y menos la tortura. Pero aún al hambre y al dolor nos avenimos si tenemos conciencia de su sentido, y la muerte puede ser una verdadera liberación para el héroe o el santo. Lo trágico es padecer todo eso con pérdida de sí mismo; no lograr reconocerse como persona, no poder decidir su destino, estar reducido a la condición de animal que recibe golpes y lame la mano de su amo, o de cosa que se lleva y se trae, se manipula y se desecha sin tener en cuenta lo que cada uno vive desde dentro. Por eso es importante la conciencia y la lucha por la conservación de tu ser hombre y el ser hombre de los demás.

HaTuEY.-Muerto el hombre, perdido el hombre. Allí está todo.

Bartolomé.-No todo, porque la humanidad se puede perder aunque siga latiendo el corazón del hombre, aunque sea capaz de caminar, ver, comer, fornicar, dormir, pensar. Para los hombres, en la existencia genuina hay algo más que llanamente vivir o morir: pueden perder su identidad, lo que ellos tienen de más propio, alienándose de sí mismos; pueden ser despojados de su capacidad de decidir libremente, por la violencia o por medios más sutiles que penetran hasta el fondo del alma; pueden ser degradados a seres inertes. La cosificación, la alienación, eso es lo peor, ies trágico! Eso representa la conquista para nosotros.

Hatuey.-Usas las palabras difíciles de tus doctores. ¿Cómo son?, ¿alienación, cosificación? Quiero comprenderlas bien: alienación, cosificación es 
cuando tratan al hombre como animal, cuando lo manejan como cosa. ¿No es cierto?

Bartolomé-Eso es, justamente. Y lo has dicho con la mejor de las comparaciones, porque el alienado se pierde en una acción sin libcrtad ni sentido, como la mula que gira en la noria. Pero el hombre puede también recupcrar la condición perdida y sobrepasarla. Puede llegar a zonas cada vez más altas de la conciencia, de la acción sobre la naturaleza y de la comunicación con sus hermanos en la tierra. La realidad humana no es unidimensional: tiene altura. Por eso todos los hombres son capaces de levantarse, caer y volver a levantarse; de mudar la condición y de ser varios en una vida. Esto los diferencia radicalmente de los animales y de las cosas. Es su prenda más valiosa.

Hatuey.--Tú dices que el hombre es uno. Pero Hatuey es distinto de Bartolomé y de un negro bozal en la raza. En eso no son uno. Esa diferencia no la cuentas, pero hace estimar a unos y despreciar a otros, disfrutar a unos y sufrir a otros.

Bartolomé.-Escucha bien, amigo. ¿Acaso no podemos comunicarnos todos y ponernos en razón y hacer pactos si queremos? ¿No se juntan los hombres y las mujeres de un pueblo con los de otros y tienen hijos y los aman por igual? ¿Juntos no se alegran, sufren, se salvan o se pierden, aunque sea distinta su raza? ¿Es imposible esto?

Hatuey. - Hasta hoy nada he visto que dé razón a lo que dices. Cada pueblo vive solo y lucha solo por su vida. Blanco e indio no sienten igual, aunque usen las mismas palabras. Claro que pueden entenderse hablando; ¿eso es ser uno para ti?

Bartolomé.-Sí. Concedes, entonces, que los hombres pueden ser uno en esto. Sin embargo - y ahí está la razón de tu duda- la humanidad se encuentra dividida. Se ha escindido en el curso de la historia. Como las aguas que caen sobre una montaña y discurren, de una parte y de otra, en dos vertientes, asi también la condición del hombre se ha quebrado, polarizándose. En el hombre histórico hay el polo de la negación y el de la afirmación, el de ser menos y el de ser más, el de la autenticidad y el del malogro.

Hatuey,-De un lado los amos y de otro los esclavos. Esto es claro y lo comprendo; en cambio, la unidad que dices existe entre los hombres es como humo que no puedo coger con la mano. El esclavo es distinto.

Bartolomé. - La esclavitud es un hecho crudo y doloroso. Es el abominable hecho de la negación del ser del esclavo. Pero aun en ese caso la unidad existe, porque la esclavitud es un modo de ser hombre, justamente el modo defectivo de serlo en la relación con un amo, o mejor dicho, dentro de la estructura señorio-esclavitud. En eso la dominación de unos hombres sobre otros, al degradar al ser, muestra su sustancia destructora, su maldad esencial.

Don Drego.- ¿De dónde has sacado, Bartolomé, que la dependencia de unos hombres respecto a otros es mala? ¿Puedes imaginar gentes que vivan en común sin lazos de dependencia? ¿Habría paz y orden en la tierra faltando 
una firme sujeción a quienes tienen en sus manos la responsabilidad del cumplimiento de la ley? Sin la ley y sin su garantía, que es el dominio de los gobernantes sobre los gobernados, la anarquía destruiría la sociedad. Además, así es en todo. Suprimido el apoyo de los demás, nada prosperaría en el mundo. Ésta es la ley, inclusive para los animales y los seres inanimados: quítale los cimientos a una casa y se cae; priva de su madre al cachorro y muere.

BARTOLOMÉ.-Concedo por entero tu argumento sobre la dependencia; voy incluso más lejos que tú y digo: todo excepto Dios implica una dependencia en su ser, pues todo nace de otro o necesita de él. Algunas veces la dependencia opera en dos direcciones, ya que el dependiente es de algún modo también necesario al otro. Están condicionados el uno por el otro, y en la medida en que no pueden existir sino juntos, forman una unidad, como un todo concertado.

DON Diego.-Cuando te lo propones, Bartolomé, sabes razonar sin error y devanar el hilo del discurso más complicado. Déjate, pues, de majaderías como que la dominación es el dominio y que la conquista es mala para estos bárbaros.

HatueY.-iEspañolcs al fín, se ponen de acuerdo rápido contra el indio, contra su libertad! No te reconozco, Bartolomé.

Bartolomé.-Hombre de poca fe. Espera y verás. He concedido algo cierto y que salta a la vista de quienquiera tenga los ojos abiertos. Tú, querido Ernesto, los tienes siempre en vela y no puedes ignorar la universal dependencia. Pero lo mismo no vale para la dominación.

DON DIEGo.- Una va con la otra; si hay dependencia, hay dominación.

BarTolomé--No siempre, y por eso conviene distinguir cuidadosamente ambos conceptos. Considera este caso: el cicgo y su lazarillo están en una neta relación de dependencia. Sin el muchacho que lo guía, el ciego no podría aventurarse por caminos que no conoce y estaría expuesto a mil acechanzas. Pero no cabe decir que el muchacho domina al ciego y que éste hace la voluntad del lazarillo.

Don Diego.-Claro que la cosa no es así; pero considera el caso del chico. Es sabido que los mendigos ciegos oprimen y explotan a los infelices que les sirven de ojos. Apenas si les dan de comer, los menosprecian y los muelen a palos peor que a perros.

Bartolomé.-Justamente ése es un buen ejemplo de dominación. Dominar - diremos usando tus propias palabras-implica oprimir, explotar, menospreciar a un hombre. El menosprecio, la explotación y la opresión bastan para degradar a quien los sufre. Esta degradación es la secuela de la dominación.

Hatuey.-Eso es lo que los españoles hacen con nosotros; sólo los ciegos no lo ven...

BARTOLOMÉ-Permíteme, Ernesto, terminar mi argumento. Hay algo más que podcmos extraer del análisis que estamos haciendo. El lazarillo es dominado por el ciego y, ademâs, dependiente de él. Lo más probable es que sea un 
niño huérfano, expuesto a morir de hambre abandonado a su suerte y que un alma cándida puso bajo la supuesta protección del ciego. Por eso el lazarillo es dependiente del mendigo tanto como éste lo es del niño. La dependencia es recíproca, por lo menos en este caso.

Hatuey.-Sin el ciego, el nin̄o muere; sin el niño, el ciego muere. ¿Eso quieres decir?

BARTOLOMĖ.-Eso precisamente.

Hatuey.-Pero un ciego no depende del lazarillo como el lazarillo depende del ciego.

BARTOLOMÉ.-En efecto, son mutuamente dependientes, pero por razones y de modos diversos.

HATUEY.-iSiempre es así?

BARTOLOMÉ.-No necesariamente. Dos personas pueden depender la una de la otra en el mismo sentido. Por ejemplo, los amantes son dependientes por el afecto que se tienen y que les pide estar cerca el uno del otro. Pero hay casos de amor en que la dependencia vale de un solo lado. No siempre el que ama es amado. Aquí, de seguro, uno es el que depende por el amor mientras el otro puede ser indiferente. ¿no?

Hatuey.-Pero en el universo todo depende de todo; es lo que dicen ustedes,

BARTolomé-Sí, pero éstas son especulaciones metafísicas que mejor dejamos descansar ahora para no perder de vista el ejemplo. Decíamos que el ciego depende del lazarillo y éste del ciego. Por otra parte, el ciego domina al muchacho, pero éste no domina al ciego. Por consiguiente, en esta relación ciego-lazarillo hay dependencia y hay también dominación, que son, como se nota, cosas distintas. La primera es relación recíproca y la segunda no, ya que hay dominación del niño por el ciego sin dominación del ciego por el niño.

Don Dieco.-Te equivocas, Bartolomé. El lazarillo tambiên domina al ciego. Estos rapaces se burlan de sus amos y suelen vengarse cruelmente de ellos luego de sufrir por un tiempo.

Bartolomé.-En ese caso yo hablaría de conatos de revuelta, actos de defensa del dominado, que pueden terminar en la rebelión total, pero no suponen sujeción del otro. Allí no hay dominación ni pucde haberla, salvo que se inviertan los papeles, el ciego pase al servicio del lazarillo y éste to oprima y lo maltrate, obrando con la misma inhumanidad que aquél.

HatueY.-Siendo dominado, uno no domina. Está claro.

Bartolomé-Si no, busquen un solo caso que pruebe lo contrario. No lo hay.

Don Diego.-Pues yo creo fácil encontrarlo; la madre y el niño, por ejemplo, están en ese caso. Ambos son dependientes y, a la vez, reciprocamente dominadores y dominados. $\measuredangle$ No has visto a los chicos salirse siempre con la suya y llevar y traer a la madre o al padre? ¿Y no has visto a éstos, perdida la paciencia, darles una azotaina como les viene en gana? 
Bartolome.-Discúlpame, Diego, pero tengo que decirte que tu ejemplo no es bueno y que vuelves a confundir dominación con dependencia. Si bien normalmente, en el caso que pones, hay dependencia y muy fuerte a lo largo de muchos años, no hay estrictamente dominación - normalmente, repito-, ni siquicra de un solo lado. Pero cuando padres e hijos entran en el círculo de la dominación -y por desgracia ocurre más de una vez- entonces se advierte claramente que también uno es el dominado y otro el dominador. La recíproca no se da. Recuerden esos niños que nunca llegan a pensar ni a obrar como mayores. Dominados por su padre o por su madre, o por ambos, han sido frustrados en su maduración, en el logro de su propia personalidad. Están alienados. $\mathrm{Y}$, ciertamente, en cuanto se hallan dominados no tienen la posibilidad de actuar contra el yugo que les imponen sus padres.

Don Diego.-El extremo en que te pones es una perversión del lazo sagrado de la paternidad.

BARTOLOMÉ-El hecho de que la natural dependencia entre padres e hijjos se pervierta cuando los padres dominan a los hijos muestra precisamente que la dependencia en sí misma es neutra. Dependemos de otro cuando necesitamos de él o estamos condicionados por él, sea que nos dirija o nos auxilie. Esto no es malo ni bueno; lo malo es la dependencia que implica dominación, la dependencia con dominación.

HatueY.-Como la del siervo indio sometido al patrón blanco.

Bartolomé---Siervo y patrón, amo y esclavo son casos del lazo de dominación en que se pueden observar muy bien los rasgos característicos, el sentido profundo y las consecuencias de esta condición humana. Sugiero aprovecharlos para ir más a fondo en el análisis si el Gobernador no se fatiga con tanto discurso.

Don Diego.-Esto no es Salamanca, ciertamente, y no estoy yo aquí para oír distingos escolásticos; pero continúa, veremos hasta dónde llegas.

Hatuex.-El amo oprime al esclavo, se queda con sus riquezas, castiga y si quiere mata al esclavo y también a su familia. Todos sabemos esto en nuestra tierra. Ésa es la dominación para nosotros. No sé si tus fórmulas lo hacen entender claramente.

BakTOLOMÉ.--Sin duda, porque lo que digo significa que el dominador decide la suerte del dominado como mejor le conviene; éste, en cambio, no tiene poder sobre su propia vida y menos puede decidir la suerte del dominador. Con la pérdida básica de la libertad de decidir el hombre dominado tiene menoscabado su ser. Como consecuencia, el dominador prospera a costa del dominado y éste languidece, manipulado en provecho del dominador. En esa condición tenemos ahora a los naturales.

Don Diego.-iCabe acaso dudar de que ningún hombre en ninguna circunstancia puede estar más cosificado - como tú dices- que cuando lo convierten en trozos de comida como lo hacen los indios? IEh, Bartolomé! ¿Qué replicas a eso? 
BartolomÉ-Digo lo mismo respecto a ellos y sus usos que respecto de nosotros y nuestras costumbres. El canibalismo es un crimen horrible, como lo es quemar vivos a prisioneros o atravesar a los niños indios con las espadas. Eso lo hemos hecho nosotros. Condeno tal violencia, como todo cristiano está obligado a condenarla, y por eso creo que la guerra debe terminar.

DON DIEGO.-Terminará cuando estos bárbaros se sometan, dejen sus prácticas sanguinarias y sean reducidos a la fe. iCuánta razón tuvo quien dijo que en América la voz del Evangelio sólo se escucha allí donde los indios han escuchado también el ruido de las armas! La nuestra es una cruzada, una guerra santa que salvará a todos los paganos aunque sea contra su voluntad. Tenlo muy presente, protector de indios.

Bartolomé.-La voz del Evangelio es la de la paz y el amor. ¿Cómo podría amparar la guerra o servirse de la violencia?

Don Diego.-Te olvidas fácilmente que nuestra acción tiene la bendición papal. No le ocultes a tu amigo que el Santo Padre Alejandro VI les dio a los Reyes de España y a sus sucesores la plena y omnímoda potestad, autoridad y jurisdicción sobre las islas y continentes descubiertos o por descubrir en cste Nuevo Mundo. Así pues, está claro, Hatuey, que todos ustedes deben someterse al dominio de nuestro monarca.

Hatuey.-Estaría loco tu Santo Padre dando lo que no era suyo. No lo reconozco, no lo obedezco, no me parece santo haciendo esto.

Don Diego--iCállate ya, pagano! Y tú, Bartolomé, mejor obra cumplinías enseñándoles el Evangelio a éstos por cualquier medio.

BARTOLOME.-Eso quiero hacer por la paz y no por la espada.

HatueY.-Ciego eres, hermano. Él quiere más guerra para ser más rico y tener más esclavos que lo sirvan. Iguales son todos los blancos. La guerra cría riqueza y servidumbre, por eso la aman.

BARTOLOME.-Y envenena el alma de los vencidos y de los vencedores, de los amos y de los esclavos que ella engendra. Ésa es otra consecuencia nefasta de la dominación.

HATUEY,-Los españoles se matan por conquistarnos y después huyen de nosotros. Traen aquí a mi gente en servidumbre y después se encierran en sus casas bien guardadas. Se juntan entre ellos no más; se hablan en su lengua; con sus palabras se pasan sus ideas y sus odios. No son, no quieren ser gente junto con nosotros. Son otra clase de gente que se cree por encima de los indios y de todos los siervos del mundo.

Bartolomé-Cuánta verdad llevan tus palabras, Ernesto. Los amos rechazan la relación humana con el esclavo. Se unen para hacerse más fuertes y se alejan de los oprimidos por temor. Éstos, entonces, se reconocen entre sí como oprimidos. Los amos marginan de su vida al esclavo y al hacerlo se cierran la vía al mundo de las personas; a la comunidad de todos los hombres. La humanidad resulta irremediablemente fraccionada en dos grupos opuestos; de un lado, los oprimidos, los pueblos en cautiverio, las clases dominadas; 
del otro, los opresores, los pueblos colonialistas e imperiales, las clases dominantes y explotadoras.

Hatley.-Ése es el fruto de la guerra, que si no es de liberación es guerra de conquista siempre. De naciones o de clases, es lo mismo; los fuertes avasallan a los débiles, les quitan tierras y bienes, se aprovechan de su trabajo. Nadie se acuerda de su hermano hombre, nadie sufre con su dolor ni trata de evitarlo.

Don Diego.-No sé como te quejas. Olvidas todo lo que nosotros hemos sufrido para traerles bienes que nọ tenían ni soñaban tener aquí en América: todos los bienes de la civilización occidental y cristiana, comenzando por la salvación de las almas.

HatueY.-Tu salvación es ponzoña para mi pueblo. Era libre, salió esclavo de la guerra; quedó enfermo cuando antes era sano. ¿Qué nos pretenden cobrar? ¿Un bien que no pedimos o el mal que nos hicieron al venir? ¿Cuántos años van a pasarnos la factura por este regalo envenenado?

Bartolomé-Tienes razón, Ernesto. No sólo los individuos, sino también las naciones sufren la alienación. La dominación repite aquí su esencia corrosiva. Las naciones oprimidas pierden la posibilidad de ser ellas mismas, son privadas de vigor creador y de alcgría de vivir. $Y$ noten que en las naciones oprimidas el siervo sufre doble la dominación del amo y la del extranjero invasor.

Hatuey.-El mismo opresor son ambos.

BaRTolomé.-No siempre. Puede haber gentes de la propia nación oprimida que la traicionan. Por haccrlo y por aceptar la dominación de su patria conservan sus propiedades, reciben riquezas y honores y les es concedido un aparente trato de hombres libres. Mientras tanto, la masa del pucblo sufre el destino de la nación en toda su dureza.

HATUEY.- Hasta hoy me negaba a aceptar que un pueblo pudiera engendrar gusanos que lo niegan, felipillos, quislings. Voy entendiendo ahora cómo es fácil conquistar y mantener dominadas a grandes naciones: hijos suyos, desde dentro, las quiebran y las entregan al enemigo opresor.

Bartolomé-Y también es fácil de entender que la dominación no es nada simple ni se aplica a un solo tipo de sujetos, ni del mismo modo. Puede multiplicarse, reforzarse y combinarse de varias suertes. Hemos visto que hay personas doblemente y hasta triplemente dominadas; por ejemplo, el siervo en una nación cautiva o las mujeres...

Hatuey.-Serán las cristianas...

BARTOLOMÉ-... y las musulmanas y otras. Pero aguarda, que lo que estoy diciendo es importante para entender el concepto que nos interesa. Hay dominación de muchas especies: de individuos, de pueblos, de sexos y otras formas más. Estas formas pueden combinarse de varias maneras, dando por resultado estructuras incluso muy complejas. Puede haber dominado que a su vez sea dominador.

Hatuey.-Un esclavo que sea amo no lo hay en rigor. 
Bartolomé.-Sí, por supuesto. A este propósito, volvamos a lo que decía de las mujeres. En lo que toca a las indias, no creo que su condición sea mucho mejor que la de las españolas.

DON DiEGo.--iCómo puedes hablar de ese modo, Bartolomé! Ofendes a las matronas españolas comparándolas con las mujeres indias. Olvidaré que cres fraile y te daré tu merecido si continúas hablando así. Sabes bien que las nativas, como sus maridos, están degradadas por costumbres bestiales.

HATUEY,-Pero bien que las persiguen tus soldados, Gobernador; las violan, se las llevan y las abandonan preñadas. Eso hacen, tú lo sabes bien. ¿Por qué hablas otra cosa?

DON DIEGo.-Me quieres hacer pasar por mentiroso y te puede costar caro. Tú eres quien miente cínicamente. He prohibido a mis soldados que tengan trato alguno con las indias; les he ordenado que no se rebajen a buscarlas, ni les den pretexto para quejarse de ofensas, y menos les hagan hijos que bastardean los nombres españoles.

HatueY.- Nosotros no vemos eso. Vemos lo que los españoles hacen con nuestras mujeres, y no nos extraña sabiendo cómo tratan a las de su nación. iPobres!, las crían para el placer de los hombres; les enseñan no a trabajar sino a arreglarse y actuar para atraer a los varones. No tienen un modo natural de ser.

DON Diego.-iNatural, natural!, una palabra que suena muy bonita y mañosamente la empleas para cubrir muchas cosas reprobables. Bien sabemos a qué viciosas prácticas «naturales» se dedica tu gente.

Bartolomé.- Hemos de conceder, Ernesto, que tales excesos, producto de la ignorancia y la superstición, existen entre los indios. Pero a medida que se extiende el aura civilizadora de la palabra de Jesucristo las desviaciones desaparecen.

HATUEy,-Observa lo que pasa a tu alrededor. Quizás tu civilización trae cosas peores. Para nosotros, buenos y bellos son los cuerpos del hombre y la mujer en el amor. Amamos como la naturaleza nos pide y vamos aprendiendo libremente a hacerlo. Nadie convencerá a mi gente de que hay pecado y vicio en hacer el amor natural.

BarTolomé.--Pero tú mismo acabas de condenar la educación que se da a la mujer de ultramar porque sólo se le enseñan artes para atraer al varón, pinturas y halagos para retenerlo y satisfacerlo.

HATUEY.-Condeno ese artificio; condeno esa utilización de la mujer para satisfacer al hombre. Tampoco el varón debe servir a la mujer.

Don DiEGo.— ¿Y las indias que buscan a los españoles para sacarles dinero? Son una peste ya en la isla.

Hatuey.-iTú nos reprochas eso? Por el trabajo esclavo que debemos hacer lejos de nuestro lugar desamparamos la casa, a la mujer y a los hijos. No podemos llevarles nada para comer. Nuestras mujeres por necesidad se hacen rameras. Esa peste no se conocía aquí antes de que ustedes llegaran. 
Mi gente no sabía comprar y vender el amor; ni idea tenían de eso que ustedes llaman corrupción. Entre nosotros, varón y mujer son camaradas en el amor como lo son en el trabajo. Así han sido criados.

BARTOLOME.-Amor y trabajo van juntos para ti. iEs asi? No alcanzo, sin embargo, a ver bien la relación que pareces establecer entre la educación del hombre y la mujer y la educación para el trabajo.

HATUEY.-Esa relación es muy clara en nuestro mundo, el mundo que ustedes llaman «bárbaro». Cuando la mujer ha aprendido a trabajar con el hombre en igualdad de trato y cuando nadie es dueño del trabajo del otro, la mujer puede participar libremente en las tareas y en las celebraciones, en la vida de la tribu y en las relaciones privadas, al igual que todos.

BARTOLOME.--Es verdad que las mujeres indias trabajan bien y mucho.

HatueY.-No están ociosas como las españolas, ni se lo permitiriamos. La tribu vive y prospera con el trabajo de todos. Ese trabajo no beneficia a nadie en particular, como los ricos que hay en la sociedad de ustedes. Un indio, hombre o mujer, se ha educado en el trabajo común, participando en él; sabe perfectamente que varón y mujer están obligados a trabajar y sabe, por eso, cómo hacer trabajar a quienes están a su cargo, sean varones o mujeres...

DON Diego. -... y sabe cómo explotar a las mujeres.

HATUEY. - ... Mientras que la española se cría perezosa y mimada. El español hace lo que ella quiere si lo complace en el lecho.

DON DiEGo.--Nosotros respetamos y protegemos a la mujer y reconocemos en el hogar su reino. Ella ha nacido para el hogar - no para el lecho, como groseramente dices, indio-. Allí es plenamente soberana: manda a los sirvientes, manda a los hijos y, es verdad -en eso tienes razón-, hasta manda al marido. iNos mandan a nosotros, a los jefes! Parece broma, pero así es. Mas en la calle, en la política, en los negocios, en la guerra, allí decidimos nosotros. La mujer no está capacitada para tales menesteres; son contrarios a su natural débil. La misión de la mujer es otra, está hecha para la maternidad y para el afecto. Perdería su femineidad, es decir, su belleza, su gracia, su delicadeza, si la ponemos a hacer cosas rudas y violentas.

BARTolomé.--Reinas esclavas en su casa, eso son hasta hoy las damas cristianas no menos que las moras. Debo decírtelo, Díego, aunque ofenda tus oídos de caballero. Reducidas al cautiverio domiciliario, tratadas como niñas pequeñas, como seres sin razón ni voluntad, incapaces de discernir sobre las cosas más serias de la vida, entre las que se encuentra nada menos que su propio destino. Es cierto que la pereza y la vanidad se ceban en estas mujeres, pero no en todas. No olvidemos a las españolas del pueblo. A ésas no las miman ni les dejan un minuto de respiro en la casa o en el campo, pero tampoco les permiten obrar libremente como los varones.

HatueY.- ¿No tendrán los españoles miedo de que si sus mujeres van con ellos al trabajo y a la guerra se les rebelen o los dejen mal parados?

Don DiEgo.- ¿Quieres insinuar que no estamos seguros de nuestras mujeres? Te respondo que ustedes son los inseguros y los explotadores, pues tienen 
varias mujeres de que se sirven. Bonita moral: unas cuantas mujeres para la cama, para la casa y, por añadidura, para compartir el trabajo duro del campo.

Bartolomé.-Ahí tienes toda la razón, Diego. Aunque a nuestros hombres tampoco les faltan mujeres, la india está en peor condición en este punto. Por eso no diré que la mujer está verdaderamente liberada entre los naturales. Tan humanos en tantas cosas, aquí fallan. iQué difícil es comprender el cabal sentido de la libertad de todos los seres humanos y de todo el ser humano, cualquiera que sea el sexo, la raza o la condición del individuo! Los conquistadores ignoran este principio, pero no creo, Ernesto, que tu pueblo lo realice plenamente. Hay también cosificación y alienación en su modo de vida.

Don DiEgo.-iDonde las dan las toman! Estás cogido, indio tramposo, en tu propia trampa. No podrás escaparte. Te imaginabas que, mansamente, ibamos a aceptar todas estas historias de la mujer india trabajadora, libre y feliz. iBabas! Pero también tú estás atrapado, Bartolomé. En su desvario, ambos se enredan con artificios dialécticos, buenos para curas y leguleyos, olvidando la realidad que es firme como la tierra firme. Para quien no esté torcido en su criterio por apostasías o por propaganda subversivas, contrarias a la sana doctrina heredada de nuestros padres, es obvio que en todos los pueblos las mujeres reciben un trato diferente que los hombres, porque hay diferencias de naturaleza entre el hombre y la mujer como las hay entre unos linajes y otros o entre las razas del mundo. ¿Qué de raro tiene entonces que entre nosotros el trato sea diverso para unos y otros y que también sea diferente el sitio que ocupan en la sociedad?

Bartolomé-Las diferencias de que hablamos y que nos importan aquí son las que afectan la dignidad del ser humano. Las diversidades de los cuerpos no alcanzan sino adjetivamente la esencia del hombre. Como el amo respecto al esclavo o el blanco respecto al negro, así también la mujer no es diferente al varón en su naturaleza humana profunda, que es libertad en acto.

DoN DIEGo.-No quiero entrar en disputas teológicas que no son mi terreno. Sólo te digo, Bartolomé, que atiendas y veas si la realidad coincide con lo que predicas. Nos hablas de un mundo ilusorio que no existe ni existirá. Sin embargo, lo que aquí y ahora está en juego es muy serio para dejarse llevar por fantasías. Ten por seguro que no te permitiremos desvariar. Puedes hacer mucho daño al imperio del Rey y de Dios. ¿No ves, te repito, que usos y costumbres, mente y gustos son diversos de hombre a hombre y de pueblo a pueblo? ¿Cómo quieres tratarlos igual? Lo mismo pasa con las mujeres.

BaRTOLOMÉ-Tú lo has dicho: de hombre a hombre. Son hombres por igual. Lo que difiere es una segunda naturaleza, no profunda, aunque puede ser muy marcada y significativa. Pero en ningún caso ella justifica el avasallamiento de unos hombres por otros. Por eso he devuelto yo mis indios o, dicho más propiamente, los indios que injustamente tomé. Y todos debemos hacer igual. Mientras no procedamos de esta suerte, mientras no cancelemos en lo intimo el impulso de dominación, para los conquistadores pero también para los natu- 
rales, las mujeres no serán otra cosa que esclavos de segundo grado, siervas de siervos.

HATUEY.-Nunca para nosotros, que no oprimimos a nadie...

Bartolomé.-LOlvidas, bueno de Ernesto, a aquellos caciques que, antes de llegar nosotros a la isla, tenían a otros naturales como sirvientes suyos? $Y$ hay caciques que ahora lloran su libertad perdida pero sin escrúpulo compran hombres para que los sirvan. Ya tenemos negros esclavos de indios ricos. Es como si éstos pretendieran compensar la opresión que les ha sido impuesta contra todo derecho, oprimiendo por su parte a esos pobres africanos que la voracidad de los mercaderes internacionales arrancó de su patria. Contribuyen así con esa cruel acción en que la humanidad es altamente ultrajada; una porción numerosa de nuestra especie ha sido hasta hoy mirada como un objeto permutable y sujeta a los cálculos de un tráfico criminal; los hombres han comprado a los hombres y no se han avergonzado de degradar la familia a la que pertenecen vendiéndose unos a otros.

Don Diego.-Bien que aconsejaste tú lo que ahora pretendes condenar. A ti se debe en mucho la venida de esclavos negros a estas tierras. Unes la hipocresía a la traición.

Bartolomé.-Con igual horror que la servidumbre de los indios rechazo ahora la de los negros. Aconsejé la internación de negros que estuviesen ya trabajando como esclavos en España, y sólo de ellos. Pero en verdad les digo, confesándolo también públicamente ante ti como autoridad, que en el hondón de mi conciencia no estoy seguro de que la ignorancia o la candidez o cl amor a los indios, que me llevaron un día a dar ese terrible consejo, puedan servirme de descargo por tan grave pecado en el juicio final. Pero mi falta de ayer no me inhibirá en lo más mínimo de condenar abierta y vehementemente en adelante ése y todos los otros tráficos de mis hermanos hombres. Así contribuiré a la liberación de todos los seres humanos oprimidos, comprendidas las mujeres indias.

Hatuey.-Insisto, Bartolomé, en lo que dije. Te engañas sobre mi pueblo. Antes y después de la invasión, allí donde las poblaciones viven de acuerdo a nuestras reglas, las mujeres son iguales a los hombres porque laboran con toda la comunidad, son trabajadores a quienes nadie oprime.

BARTOLOME.-Concedo que el trabajo en comunidad es de una importancia moral enorme y nos debe hacer pensar en su significado para construir la sociedad justa. Pero la labor diaria de las mujeres, el esfuerzo igual y tal vez mayor que despliegan, pues atienden también los menesteres de la casa, no las libera de suyo si no poseen la capacidad de decidir sobre su vida y destino, sobre si quieren o no ser madres, sobre si quieren o no dedicarse sólo al hogar, sobre si quieren o no seguir con el marido que muchas veces les fue impuesto.

Don Diego.--Lo que dices, Bartolomé, es completamente ridículo, tanto que hasta el indio no te da la razón. iLa mujer fuera del hogar y en lucha contra el hombre! iIncreible! 
Hatuey.-No le doy la razón porque nuestra mujer no necesita esa liberación. Si dudan, pregúntenle a cualquiera de ellas.

Bartolomé.-Al preguntarle, Ernesto, no es seguro que la mujer nos dé una respuesta correcta. Primero, porque quizá no comprenda la pregunta por falta de esa conciencia despierta y lúcida de que antes hablé. Segundo, porque muchas, quizá la mayoría de las mujeres, nos responderían que sí están satisfechas. El buey se acomoda al yugo y termina echándolo de menos. Sobre todo porque arrojar el yugo es abandonar la costumbre, asumir responsabilidades y desafiar a los dominadores. Lo mismo ocurriría con las españolas, que tú sí consideras dominadas. También hallaríamos entre ellas una mayoría que diría que no quieren ni necesitan liberarse.

Hatuey.-Nadie es esclavo por su gusto. Si no lo han reducido por la fuerza, alguien lo ha engañado.

BarTolomé.-No te equivocas, amigo; hay esclavitudes enmascaradas. Al igual que clases sociales y pueblos que ignoran su opresión, hay muchas mujeres que están satisfechas con su suerte. Obran por ignorancia, por conformarse con satisfacciones elementales, pero sobre todo por una educación que las ha condicionado a la aceptación de los valores de los dominantes y a la defensa del orden establecido en el cual ellas están presas como en una jaula de oro.

HatueY.-Pero el trabajo común le da a nuestra mujer la libertad que neccsita, porque en el trabajo está toda nuestra vida. ¿No lo comprendes?

Bartolomé.-Sć lo que estás pensando, Ernesto: cuando el trabajo está alienado difícilmente el trabajador puede conservar su humanidad. Pero hay casos que prueban que esta condición necesaria no es suficiente. Piensa en lo que ocurre con el niño que, entre ustedes como en muchas de nuestras familias del pueblo, trabaja. No tiene libertad; se encuentra sujeto a la autoridad del padre, aunque su trabajo como tal no esté alienado pues se cumple en la comunidad familiar. Esto nos hace ver que to que cuenta es la relación entre los hombres no sólo en el trabajo sino, además, en el resto de la vida. La liberación, para las mujeres como para los siervos y para los negros esclavos, exige la transformación de todas las relaciones sociales que los desfavorecen.

Don Diego.-Al hablar así, Bartolomé, soliviantas no sólo a los indios sino también a las mujeres y a los negros, y lo haces en mis propias barbas. Te profetizo un triste final. Antes de que envenenes a los infelices y, por añadidura, a nuestras mujeres...

Bartolomé.-... disculpa, Diego, no por añadidura, sino a la vez; se trata de luchas convergentes...

Don Diego.-... antes de que los envenenes del todo - repito, y no me interrumpas cuando hablo-, te liquidaré a ti con todos los indios y negros pendencieros que haya en la comarca. Ahora, ilárguense antes de que aquí mismo tome acción contra ustedes y con mis propias manos! Pero en adelante, cuídense; nada me refrenará al aplicar la ley.

Bartolomé,-No nos quedaremos, Gobernador. Vinimos a hacerte oír cosas graves y verdaderas. Partimos convencidos de que ya sabes quién está en el 
error, quién en la verdad y sobre qué volcán estás sentado. Pero dime: ¿y la proposición que te hizo Hatuey? ¿Qué respondes a ella?

Don Diego.-Loco estaría de aceptar pactos con él. O se rinde, acatando la autoridad del Rey y la verdad de nuestra religión, o muere. iFuera, de una vez, antes de que sea demasiado tarde! 